\title{
The Effects of Mobile Application on Acceptance, Learning Flow, Knowledge, and Study Crafting for Nursing Students
}

\author{
Jung-Ha Park1), Sang-Wha Lee2)
}

\begin{abstract}
The present study was carried out to develop an application for women's health nursing and to test changes in the participants' acceptance of new technology, learning flow, knowledge, and study crafting. Data were collected between March 4 and April 15, 2019. The research subjects were 119 third-year nursing students attending one nursing school in $\mathrm{K}$ region. The program lasted 6 weeks. The collected data were analyzed using the SPSS Win 24 Program; general characteristics were measured using the mean, standard deviation, frequency, and percentages, while research variables were measured using a paired t-test. The results showed that the acceptance of new technology was statistically valid. Significant results were also obtained in the area of learning flow and the sub-areas of attempt-skill balance, having a clear goal, detailed feedback, behavior-perception match, concentration on tasks, sense of control, loss of self-consciousness, changed sense of time, and self-purposeful experience. The participants' knowledge increased significantly after the intervention. Significant results were also obtained in the area of academic crafting and the sub-areas of task crafting and relationship crafting. Given these research results, further study is needed on the development and applicability of new educational methods, such as applications, that can be applied to nursing students.
\end{abstract}

Keywords: Acceptance Intent, Flow, Knowledge, Study Crafting, Smartphone, Application

\section{Introduction}

\subsection{The Need for this Study}

The field of Women's Health Nursing focuses on health issues that impact women throughout their entire lives, including anatomy and pathogenesis, particularly involving pregnancy, childbirth, prenatal health, and the female reproductive organs[1]. As the terminology used in women's health nursing is relatively unfamiliar to nursing students, given the wide range of

Received (May 6, 2019), Review Result (1st: June 1, 2019, 2nd: August 6, 2019), Accepted (September 10, 2019)

1) (Assistant Professor) 47011 Dept. Nursing Science, Dongseo Univ., Jurye-ro, Sasang-gu, Busan, Korea email: suha2002@gdsu.dongseo.ac.kr

2) (Assistant Professor, Corresponding Author) 50811 Dept. Nursing, Gimhae Univ., Samanro 112 Bungil 198, Gimhaesi, Korea

email: 1967shl@naver.com 
topics covered in clinical practice, many learners report difficulties in mastering this material. Nursing education is needed to introduce methods of learning that expand students' abilities beyond passive learning and theoretical knowledge[2]. Nursing education, in particular, needs to develop a diverse range of learning and teaching methods by evaluating students' educational performance at graduation. For this reason, many nursing departments have recently adopted methods such as problem-centered learning[3], flip learning[4], peer learning[5], and simulation[6].

Although problem-centered learning methods are effective in cultivating self-directed learning and higher thinking skills for problem solving, students' own learning ability (i.e. year and grades) can have an impact[3]. Flip learning, based on the concept of prior learning, is a method in which students learn actively on their own before the course and apply knowledge acquired in class to case-based or problem-centered learning methods. Students report high levels of stress, due to the extensive time and effort needed to study new material; however prior learning can improve concentration in class[7].

Despite the advantages of these methods, students continue to experience stress from shallow learning without depth and to feel angry at their own pace of learning because they are forced to complete one semester of classes in an 8-week nursing curriculum in which clinical practice is taught in parallel[8]. To respond to learners' needs, methods of learning must be re-examined, especially in situations where students are less advanced or expected to learn unfamiliar information. To enjoy and continue learning, learners need a learning method and repeated experiences that suit them well.

Lecture-style approaches have the advantage of systematically and efficiently communicating objective and logical information within a given time limit, enabling students to learn a body of information[3]. In lecture-style classes, the extraction of educational content to use in a later test significantly strengthens student learning. It can also be a reasonable learning and time-allocation strategy because it accurately evaluates what learners do and do not know[9].

As South Korea is a strong IT nation and most citizens use smartphones or tablet PCs, the Department of Education has applied its vision, "Class revolution through smart education" when implementing education policies since 2011[10]. In their 4-5-week study of the impact of flashcard and quiz applications on college students taking teaching-administration classes, Jeong, Kwon, and Kim[11] identified various effects in academic achievement and self-led learning ability. Park and Kim[12] have developed and applied an application to train nursing students in the use of high-risk drugs; they too found learning effects.

Many teaching and learning methods currently used in nursing education vary by 
application year, depending on whether the class is difficult or mandatory[4][7][13][14]. Learners find it difficult to master women's health nursing because the terminology is unfamiliar and relatively few studies have tested specific learning or teaching methods in the areas of pregnancy, birth, or prenatal health[7][15]. The advantage of using an application is its mobility and portability, as the educational program is not limited by time or place, learners have the opportunity to learn at a time and place that suit them[16].

The present study has used teaching and learning methods based on women's health nursing applications to help students enjoy learning beyond the lecture halls. Through this approach, they can discover what they do and do not know through repeated experiences and quizzes, which promote self-learning. The present study sets out to identify the changes generated by this approach in the students' learning flow, study crafting, acceptance of new technology, and knowledge of women's health nursing.

\subsection{The Purpose of this Research}

The purpose of this research is to implement an application in women's health nursing education and to identify changes in nursing students' acceptance of new technology, learning flow, knowledge, and study crafting; it also provides basic data that can be used to popularize such applications.

\section{Research Methods}

\subsection{Research Design}

A one-group pre-test/post-test design has been used to incorporate the educational content of women's health nursing into an application and identify its effects on students' acceptance of new technology, learning flow, knowledge, and academic crafting.

\subsection{Research Subjects and Data Collection}

The 119 research subjects were all third-year students, enrolled in a women's health nursing class in the nursing department of a single university in K City; they fully understood the purpose of this research and gave their informed consent in agreeing to participate. Data were collected between March 4 and April 15, 2019; the intervention lasted 6 weeks. Of the 119 subjects originally selected, none withdrew or failed to complete the program. A sample size 
of at least 57 subjects was needed, given an effect size of .5 , a significance level $=.05$, and statistical power $=.95$ using the $\mathrm{G}^{*}$ power 3.1 .7 program[17]. The sample size of 119 was therefore sufficient.

\subsection{Research Tools}

\subsubsection{Learning Flow}

To enhance learning flow, we used the adult learning-flow tool developed by Kim et al.[18], based on research carried out by Csikszentmihalyi[19], Jackson and Marsh[20]. The tool consisted of 29 items across the 9 sub-areas of "attempt-skill balance" (3 items), "having a clear goal" (3 items), "detailed feedback" (3 items), "behavior-perception match" (3 items), "concentrating on the task" (3 items), "a sense of control" (3 items)," "loss of self-consciousness" (3 items), "a changed sense of time" (3 items), and "self-purposeful experience" (5 items)." Items were measured using a 5-point Likert scale, with responses ranging from 1 (Strongly disagree) to 5 (Strongly agree). A higher score indicated a higher level of flow. The Cronbach's a was .68-.90 in the research by Kim et al.[18] and .953 in the present study.

\subsubsection{Study Crafting}

To measure academic crafting, we used the job-crafting scale developed by Slemp and Vella-Brodrick[21], validated in a Korean version by Yim et al.[22], and revised for college students and validated by Choi and Shin[23]. The scale includes 14 items, spread across task crafting (4 items), cognitive crafting (5 items), and relationship crafting (5 items). Items are measured using a 5-point Likert scale, with higher scores indicating a higher level of academic crafting. The Cronbach's alpha was .89 in the research by Choi and Shin[23] and .901 in the present study.

\subsubsection{Acceptance of New Technology}

The acceptance-of-new-technology scale developed by Kang[24], based on the research by Taylor and Todd[25] and Choi and Shin[26], was adapted to suit this research. The tool consisted of the following 4 items: "I intend to learn using the mobile app," "I feel the need to use the mobile app," "I intend to actively use the mobile app," and "I intend to use the mobile app, if given the right environment." Items were measured using a 10-point Likert 
scale, with higher scores indicating a higher intention to accept the new technology. The Cronbach's alpha was 952 in this study.

\subsubsection{Knowledge}

The knowledge tool consisted of 20 items in the areas of fetal health assessment, early-pregnancy bleeding, late-pregnancy bleeding, pregnancy Induced Hypertension and gestational diabetes problems, the characteristics of 5 elements of labor, and physiology of puerperial period, as 5-choice questions. The knowledge-evaluation items, grouped by subject, centered around the Korean Society of Nursing Science learning goals for educating nursing students[1]. Correct responses received 1 point and incorrect responses 0 points. Higher scores indicated a higher level of knowledge.

\subsubsection{Composition of Women's Health Nursing Applications}

Women's health nursing applications were composed according to the ADDIE (Analysis, Design, Development, Implementation, Evaluation) model. In the first stage, which is the analysis stage, the educational contents were composed through comparison and analysis of the women's health nursing II teaching plans from one national and one private university from each region among the nationwide nursing departments, as well as women's health nursing learning objectives proposed by the society of nursing science. The design stage included the contents of the education method's application purpose, weekly learning goals and contents, the question composition method for evaluation contents with the delivery method of user interface, and finally the selection of evaluation tools. In the development stage, the screens were composed and prototypes were demonstrated in order to graft the composed education contents and evaluation questions onto applications through brainstorming the screen conception between the researcher and expert groups. Especially for the evaluation by unit the question examples were randomly changed when re-evaluating post relearning, so that simple memorization would not change the evaluation results. In the implementation stage, professors from other universities teaching women's health nursing were asked to use the application. In the evaluation stage, the contents were finalized through discussion with expert groups on problems that arose during the implementation stage.

\subsection{Data Analysis Method}

Collected data were analyzed using the SPSS WIN 24 Program. The subjects' general 
characteristics were analyzed using descriptive statistics; the t-test and one-way analysis were used for subjects' prior acceptance of new technology, study-craft, learning-flow, and knowledge, the paired t-test method was used to test differences in the subjects' acceptance of new technology, learning flow, knowledge, and academic crafting before and after the intervention.

\section{Result}

The women's health nursing application was divided into teaching plans, learning, and quiz areas. Learning consisted of 10 sub-areas of content. The quizzes were also divided into 10 sub-areas and 50 5-choice questions.

Of the research subjects $78.2 \%$ were female; the mean age was $27.55 \pm 8.67$. Overall, $45.4 \%$ of the students were satisfied with the department; $52.9 \%$ had iPhones as smartphones; only $35.5 \%$ had experience of using education applications [Table 1]. The research subjects' acceptance of new technologies $(\mathrm{t}=5.712, \mathrm{p}=.018)$, study-crafting $(\mathrm{t}=16.153, \mathrm{p}=.000)$, learning-flow $(\mathrm{t}=4.634, \mathrm{p}=.033)$, and knowledge $(\mathrm{t}=6.860, \mathrm{p}=.010)$ showed significant differences. The type of smartphone in possession made a significant difference to study-crafting $(\mathrm{t}=4.426, \mathrm{p}=.038)$ and learning-flow $(\mathrm{t}=6.264, \mathrm{p}=.014)$. Experience of educational applications was different from study-crafting $(\mathrm{t}=4.372, \mathrm{p}=.039)$. Satisfaction with the major made a significant difference to acceptance of new technology $(\mathrm{t}=7.835, \mathrm{p}=$ $.006)$, study-crafting $(\mathrm{t}=40.766, \mathrm{p}=.000)$, and learning-flow $(\mathrm{t}=14.333, \mathrm{p}=.000)$.

To verify the usefulness of supplementary applications used in women's health nursing lectures, this research only used some of the demographic variables; however, one can infer that these variables reflect socioeconomic status, motivation for choosing the subject, and prior learning ability.

The differences in accepting new technology, learning flow, knowledge, and academic crafting before and after the women's health nursing application are shown in Table 2 . Acceptance of new technology significantly improved from $7.92 \pm 1.68$ before the intervention to $8.48 \pm 1.88$ afterwards. Learning flow significantly improved from $2.93 \pm 0.60$ before the intervention to $3.30 \pm 0.80$ afterwards. Among the sub-areas, attempt-skill balance was $3.43 \pm 0.69$ before and $3.66 \pm 0.78$ after the intervention; having a clear goal was $3.49 \pm 0.69$ before and $3.76 \pm 0.84$ after the intervention; detailed feedback was $2.98 \pm 0.73$ before and $3.38 \pm 0.88$ after the intervention; behavior-perception match was $2.70 \pm 0.81$ before and $3.15 \pm 1.02$ after the intervention; and concentrating on tasks was $2.71 \pm 0.83$ before and $3.08 \pm 1.00$ after the 
intervention. All showed significant increases. The sense of control was $2.88 \pm 0.76$ before and $2.88 \pm 0.76$ after the intervention; the loss of self-consciousness was $2.51 \pm 0.87$ before and $3.00 \pm 1.05$ after the intervention; having a changed sense of time was $3.15 \pm 0.86$ before and $3.48 \pm 0.85$ after the intervention. In addition, self-purposeful experience was $2.53 \pm 0.89$ before and $3.04 \pm 1.09$ after the intervention; these too all showed significant improvements.

Knowledge significantly increased from $6.71 \pm 2.57$ before the intervention to $14.17 \pm 4.11$ afterwards. Academic crafting significantly increased from $3.65 \pm 0.56$ before the intervention to $3.87 \pm 0.61$ afterwards. Among the sub-areas, task crafting significantly increased from $3.54 \pm 0.71$ before the intervention to $3.82 \pm 0.75$ afterwards, while relationship crafting significantly increased from $3.43 \pm 0.67$ before the intervention to $3.72 \pm 0.77$ afterwards.

Program evaluations are shown in Table 3. The subjects received the highest scores in the following areas: "It is convenient to learn using the app because it is not restricted by place;" "The information in the educational material and is useful and trustworthy;" and "I am satisfied with the overall educational content" in that order. The item, "It is convenient to learn using the app because it saves time" received the lowest score.

[Table 1] Differences of Acceptance of New Technology, Study Crafting, Learning Flow and Knowledge According to General Characteristics $(\mathrm{N}=119)$

\begin{tabular}{|c|c|c|c|c|c|c|c|c|c|c|}
\hline \multicolumn{2}{|c|}{ Characteristics } & \multirow{2}{*}{$\begin{array}{c}\mathrm{n}(\%) / \\
\mathrm{M} \pm \mathrm{SD}\end{array}$} & \multicolumn{2}{|c|}{$\begin{array}{l}\text { Acceptance of new } \\
\text { technology }\end{array}$} & \multicolumn{2}{|c|}{ Study crafting } & \multicolumn{2}{|c|}{ Learning flow } & \multicolumn{2}{|c|}{ Knowledge } \\
\hline \multirow{2}{*}{ Gender } & Male & & $\begin{array}{c}\mathrm{M} \pm \mathrm{SD} \\
34.35( \pm 5.59)\end{array}$ & \multirow{2}{*}{$\begin{array}{l}\mathrm{t} / \mathrm{F}(\mathrm{p}) \\
5.713 \\
(.018)^{-}\end{array}$} & \multirow{2}{*}{$\begin{array}{c}\mathrm{M} \pm \mathrm{SD} \\
56.23( \pm 8.64) \\
49.60( \pm 7.07)\end{array}$} & \multirow{2}{*}{$\begin{array}{c}\mathrm{t} / \mathrm{F}(\mathrm{p}) \\
16.153 \\
(.000)^{\prime \prime \prime}\end{array}$} & \multirow{2}{*}{$\begin{array}{c}\mathrm{M} \pm \mathrm{SD} \\
81.27( \pm 20.36) \\
73.94( \pm 13.68)\end{array}$} & \multirow{2}{*}{$\begin{array}{c}\mathrm{t} / \mathrm{F}(\mathrm{p}) \\
\\
4.634 \\
(.033)^{-}\end{array}$} & \multirow{2}{*}{$\begin{array}{c}\mathrm{M} \pm \mathrm{SD} \\
5.08( \pm 1.98) \\
6.42( \pm 2.39)\end{array}$} & \multirow{2}{*}{$\begin{array}{r}t / F(p) \\
6.860 \\
(.010)\end{array}$} \\
\hline & Female & $93(78.15)$ & $30.83( \pm 6.89)$ & & & & & & & \\
\hline \multirow{3}{*}{ Age(yr) } & $20 \sim 21$ & $38(31.93)$ & $32.32( \pm 6.55)$ & \multirow{3}{*}{$\begin{array}{l}1.868 \\
(.156)\end{array}$} & $48.32( \pm 6.86)$ & \multirow{3}{*}{$\begin{array}{l}4.055 \\
(.573)\end{array}$} & $68.58( \pm 11.93)$ & \multirow{3}{*}{$\begin{array}{l}6.118 \\
(.924)\end{array}$} & $6.05( \pm 1.80)$ & \multirow{3}{*}{$\begin{array}{l}1.139 \\
(.361)\end{array}$} \\
\hline & $22 \sim 39$ & $58(48.74)$ & $32.09( \pm 6.51)$ & & $51.78( \pm 8.56)$ & & $78.40( \pm 16.67)$ & & $5.91( \pm 2.52)$ & \\
\hline & $40 \sim 53$ & $23(19.33)$ & $29.17( \pm 7.45)$ & & $53.74( \pm 6.60)$ & & $79.83( \pm 14.84)$ & & $6.78( \pm 2.76)$ & \\
\hline \multirow{2}{*}{$\begin{array}{c}\text { Type of } \\
\text { Smart-phon } \\
\text { e }\end{array}$} & Android & $56(47.05)$ & $32.68( \pm 6.36)$ & \multirow{2}{*}{$\begin{array}{l}2.744 \\
(.100)\end{array}$} & $52.64( \pm 9.01)$ & \multirow{2}{*}{$\begin{array}{c}4.426 \\
(.038)^{-}\end{array}$} & $79.25( \pm 16.16)$ & \multirow{2}{*}{$\begin{array}{l}6.264 \\
(.014)^{-}\end{array}$} & $5.75( \pm 1.96)$ & \multirow{2}{*}{$\begin{array}{l}2.709 \\
(.102)\end{array}$} \\
\hline & iPhone & $63(52.95)$ & $30.63( \pm 7.02)$ & & $49.63( \pm 6.51)$ & & $72.24( \pm 14.40)$ & & $6.46( \pm 2.65)$ & \\
\hline \multirow{2}{*}{$\begin{array}{l}\text { Experience } \\
\quad \text { of } \\
\text { Educational } \\
\text { Application }\end{array}$} & Yes & $42(35.29)$ & $32.24( \pm 6.16)$ & \multirow{2}{*}{$\begin{array}{l}0.581 \\
(.447)\end{array}$} & $53.07( \pm 7.47)$ & \multirow{2}{*}{$\begin{array}{c}4.372 \\
(.039)^{-}\end{array}$} & $78.93( \pm 15.49)$ & \multirow{2}{*}{$\begin{array}{l}3.125 \\
(.080)\end{array}$} & $6.24( \pm 2.90)$ & \multirow{2}{*}{$\begin{array}{l}0.144 \\
(.705)\end{array}$} \\
\hline & No & $77(64.71)$ & $31.25( \pm 7.09)$ & & $49.95( \pm 7.96)$ & & $73.69( \pm 15.43)$ & & $6.06( \pm 2.04)$ & \\
\hline \multirow{2}{*}{$\begin{array}{l}\text { Satisfaction } \\
\text { of Major }\end{array}$} & Satisfaction & $78(65.55)$ & $32.82( \pm 6.29)$ & \multirow{2}{*}{$\begin{array}{l}7.835 \\
(.006)^{\prime \prime \prime}\end{array}$} & $53.95( \pm 7.30)$ & \multirow{2}{*}{$\begin{array}{l}40.766 \\
(.000)^{\prime \prime \prime}\end{array}$} & $79.26( \pm 15.60)$ & \multirow{2}{*}{$\begin{array}{l}14.333 \\
(.000)^{\prime \prime \prime}\end{array}$} & $6.37( \pm 2.59)$ & \multirow{2}{*}{$\begin{array}{l}2.471 \\
(.119)\end{array}$} \\
\hline & Neutral & $41(34.45)$ & $29.27( \pm 7.10)$ & & $45.54( \pm 5.83)$ & & $68.46( \pm 13.05)$ & & $5.66( \pm 1.80)$ & \\
\hline
\end{tabular}


The Effects of Mobile Application on Acceptance, Learning Flow, Knowledge, and Study Crafting for Nursing Students

[Table 2] Changes in the Variables $(\mathrm{N}=119)$

\begin{tabular}{|c|c|c|c|c|c|}
\hline \multirow{2}{*}{ Variable } & Pre-test & Post-test & \multirow{2}{*}{$\mathrm{t}$} & \multirow{2}{*}{$p$} \\
\cline { 3 - 6 } & & $\mathrm{M} \pm \mathrm{SD}$ & $\mathrm{M} \pm \mathrm{SD}$ & & \\
\hline \hline \multirow{4}{*}{ Acceptance of new technology } & $7.92 \pm 1.68$ & $8.48 \pm 1.88$ & -3.17 & .002 \\
\hline \hline \multirow{4}{*}{$\begin{array}{c}\text { Learning } \\
\text { concentration }\end{array}$} & Attempt-skill balance & $3.43 \pm 0.69$ & $3.66 \pm 0.78$ & -3.43 & .001 \\
\cline { 2 - 6 } & Clear goal & $3.49 \pm 0.69$ & $3.76 \pm 0.84$ & -3.99 & $<.001$ \\
\cline { 2 - 6 } & Detailed feedback & $2.98 \pm 0.73$ & $3.38 \pm 0.88$ & -5.03 & $<.001$ \\
\cline { 2 - 6 } & Behavior-perception match & $2.70 \pm 0.81$ & $3.15 \pm 1.02$ & -5.08 & $<.001$ \\
\cline { 2 - 6 } & Concentration on task & $2.71 \pm 0.83$ & $3.08 \pm 1.00$ & -3.61 & $<.001$ \\
\cline { 2 - 6 } & Sense of control & $2.88 \pm 0.76$ & $3.18 \pm 0.91$ & -3.61 & $<.001$ \\
\cline { 2 - 6 } & Loss of self-consciousness & $2.51 \pm 0.87$ & $3.00 \pm 1.05$ & -4.75 & $<.001$ \\
\cline { 2 - 6 } & Changed sense of time & $3.15 \pm 0.86$ & $3.48 \pm 0.85$ & -3.62 & $<.001$ \\
\cline { 2 - 6 } & Self-purposeful experience & $2.53 \pm 0.89$ & $3.04 \pm 1.09$ & -4.74 & $<.001$ \\
\cline { 2 - 6 } & Total & $2.93 \pm 0.60$ & $3.30 \pm 0.80$ & -5.41 & $<.001$ \\
\hline \multirow{4}{*}{$\begin{array}{c}\text { Academic } \\
\text { crafting }\end{array}$} & Knowledge & $6.71 \pm 2.57$ & $14.17 \pm 4.11$ & -15.82 & $<.001$ \\
\cline { 2 - 6 } & Task crafting & $3.54 \pm 0.71$ & $3.82 \pm 0.75$ & -3.77 & $<.001$ \\
\cline { 2 - 6 } & Cognitive crafting & $3.98 \pm 0.63$ & $4.07 \pm 0.65$ & -1.50 & .137 \\
\cline { 2 - 6 } & Relationship crafting & $3.43 \pm 0.67$ & $3.72 \pm 0.77$ & -3.99 & $<.001$ \\
\cline { 2 - 6 } & Total & $3.65 \pm 0.56$ & $3.87 \pm 0.61$ & -3.79 & $<.001$ \\
\hline
\end{tabular}

[Table 3] Evaluation of the Application ( $\mathrm{N}=119)$

\begin{tabular}{|lc|}
\hline \multicolumn{1}{|c|}{ Items } & $\mathrm{M} \pm \mathrm{SD}$ \\
\hline It is generally interesting to learn using the app. & $4.48 \pm 0.61$ \\
It is easy to learn using the app. & $4.34 \pm 0.85$ \\
It is convenient to learn using the app because it saves time. & $4.31 \pm 0.84$ \\
It is convenient to learn using the app because it is not restricted by place. & $4.66 \pm 0.56$ \\
The screen structure of the app-based education is appropriate. & $4.41 \pm 0.95$ \\
The educational materials are structured in a way that is easy to understand. & $4.34 \pm 0.72$ \\
The information in the educational material is useful and trustworthy. & $4.55 \pm 0.56$ \\
The content of the educational material achieves its educational purpose. & $4.52 \pm 0.60$ \\
I am satisfied with the overall educational content. & $4.54 \pm 0.57$ \\
I want to recommend this app-based education to friends or colleagues. & $4.47 \pm 0.75$ \\
\hline
\end{tabular}

\section{Conclusion}

This study developed the content of women's health nursing education into an application; third-year nursing students downloaded it from the android market and app store and used it 
for a total of 6 weeks.

This study showed that women's health nursing application increased the acceptance of new technology, learning flow, knowledge, and academic crafting among nursing students.

The results can be inferred from a situation where all subject lecture resources were required and moving to home and the school was difficult: therefore, only certain subject resources were revised when voluntary identification of the educational content outside the lecture room was possible without any limitations based on time or place. In addition, it is believed that self-assessment can be performed after learning by unit and that the question options are randomly changed upon re-evaluation after repeated learning according to the results; this leads to a valid result in learning motivation by experiencing improvement of the assessment score through understanding rather than memorization.

\section{Acknowledgement}

This work was supported by Dongseo University, "Dongseo Cluster Project" Research Fund of 2019(DSU-20190011).

\section{References}

[1] http://www.mhnursing.or.kr/bbs/4460, May 28 (2017)

[2] Y. K. Kim, Transition of 21st Century University Educational Paradigm by Science Development: From separation to integrated, global international education, Engineering Education, (2010), Vol.17, No.4, pp.11-19.

[3] S. H. Park, A Study on Students' Instructional Preferences between Problem-based learning and Teacher-centered Learning, The Journal of Learner-Centered Curriculum and Instruction, (2016), Vol.16, No.9, pp.495-515, DOI: 10.22251/jlcci.2016.16.9.495

[4] N. Y. Lee and J. Y. Han, Nursing students' learning motivation, class participation, and class satisfaction on flipped class and teacher-centered class, The Journal of Learner-Centered Curriculum and Instruction, (2017), Vol.17, No.8, pp.253-267, DOI: 10.22251/jlcci.2017.17.8.253

[5] M. R. Yoo, M. S. Kang, H. W. Kim, H. L. Han and J. Y. Choi, The Effects of Self-directed Practice using Peer-tutoring on Confidence, Performance and Learning Satisfaction of Nursing Students in Practicing Core Nursing Skills, The Journal of the Korean Academic Society of Nursing Education, (2017), Vol.23, No.1, pp.27-36, DOI: 10.5977/jkasne.2017.23.1.27

[6] Y. A. Song and Y. J. Son, Effects of Simulation-based Practice Education for Core Skill of Maternity Nursing, Korean Parent-Child Health Journal, (2013), Vol.16, No.1, pp.37-44.

[7] B. J. Lee and S. Y. Hwang, Class Experience of the Students on "Pregnancy, Delivery and Puerperium" 
Nursing Course through Flipped Learning: Mixed Method Research, Korean Journal of Women's Health Nursing, (2016), Vol.22, No.4, pp.221-232, DOI: 10.4069/kjwhn

[8] Y. S. Kim, Experiences on Block System Class in Nursing Students, Journal of Korea Academia-Industrial Cooperation Society, (2016), Vol.17, No.6, pp.629-641, DOI: 10.5762/KAIS.2016.17.6.629

[9] H. S. Choi, T. S. Shin and E. M. Yeon, Effects of Strategy to Help Repeated Memory Retrieval on Students' Memory and Metacognitive Judgments: Moderating Effects of Academic Achievement Level, Asian Journal of Education, (2015), Vol.16, No.2, pp.315-339, DOI: 10.15753/aje.2015.16.2.012

[10]https://www.moe.go.kr/boardCnts/view.do?boardID=294\&boardSeq=34571\&lev=0\&searchType=null $\mathrm{YN}=$ W\&page $=524 \& \mathrm{~s}=$ moe\&m=0501\&opType $=\mathrm{N}$, Jun 29 (2011)

[11] J. W. Jung, H. L. Kwon and D. H. Kim, Instructional effect of mobile flashcard and assessment app use, The Korean Journal of Educational Methodology Studies, (2017), Vol.29, No.2, pp.443-466, DOI: 10.17927/tkjems.2017.29.2.443

[12] J. H. Park and M. H. Kim, Development and Evaluation of Medication Nursing Education Program based on Smartphone, Asia-Pacific Journal of Multimedia Services Convergent with Art, Humanities, and Sociology, (2019), Vol.9, No.3, pp.449-457, DOI: 10.35873/ajmahs.2019.9.3.042

[13] H. J. Kang, M. Y. Kim and H. J. Choe, Effects of Integrated Nursing Practicum by applying Simulation-Problem Based Learning on Critical Thinking Disposition, Nursing Process Competence, and Self-confidence on Core Basic Nursing Skills, The Journal of Learner-Centered Curriculum and Instruction, (2016), Vol.6, No.12, pp.495-508, DOI: 10.22251/jlcci.2016.16.12.495

[14] M. S. Je and C. W. Nam, Developing a Teaching and Learning Model using Flipped Learning for the Course of Core Fundamental Nursing Skills in Nursing Education, The Journal of Learner-Centered Curriculum and Instruction, (2017), Vol.7, No.17, pp.375-401, DOI: 10.22251/jlcci.2017.17.17.375

[15] E. J. Lee, The Effects of Lessons using Team-Based Learning on Nursing Students: Focusing on Pregnant Women Care, Asia-Pacific Journal of Multimedia Services Convergent with Art, Humanities, and Sociology, (2018), Vol.8, No.11, pp.685-696, DOI: 10.35873/ajmahs.2018.8.11.065

[16] Y. M. Seo, Y. J. Lee, Analysis of educational smartphone applications and mobile educational services trends, Proceeding of the Korean Association of Computer Education, (2010), Vol.14, No.2, pp.9-13, UCI: I410-ECN-0102-2013-370-002216328

[17] F. Faul, E. Erdfelder, A. G. Lang and A. Buchner, G*POWER 3: A flexible statistical power analysis program for the social, behavioral, and biomedical sciences, Behavior Research Methods, (2007), Vol.39, No.2, pp.175-191, DOI: 10.3758/bf03193146

[18] A. Y. Kim, H. Y. Tack and C. H. Lee, The Development and Validation of a Learning Flow Scale for Adults, The Korean Society of Educational Psychology, (2010), Vol.24, No.1, pp.39-59, UCI: G704-000199.2010.24.1.006

[19] M. Csikszentmihalyi, Flow: The psychology of optimal experience, New York: Harper \& Row, (1990)

[20] S. A. Jackson and H. W. Marsh, Development and validation of a scale to measure optimal experience: The Flow State Scale, Journal of Sport and Exercise Psychology, (1996), Vol.18, pp.17-35, DOI: https://doi.org/10.1123/jsep.18.1.17

[21] G. R. Slemp and D. A. Vella-Brodrick, The Job Crafting Questionnaire: A New Scale to Measure the 
Extent to Which Employees Engage in Job Crafting, International Journal of Wellbeing, (2013), Vol.3, No.2, pp.126-146, DOI: 10.5502/ijw.v3i2.1

[22] M. K. Lim, Y J. Ha, D. J. Oh and Y. W. Sohn, Validation of the Korean Version ofJob Crafting Questionnaire (JCQ-K), Korean Corporation Management Review, (2014), Vol.21, No.4, pp.181-206, UCI: G704-002085.2014.21.4.010

[23] Y. Y. Choi and J. Y. Shin, Validation of the Study Crafting Questionnaire(SCQ) among Online and Offline University Students, Journal of Educational Technology, (2018), Vol.34, No.1, pp.73-99, DOI: 10.17232/KSET.34.1.073

[24] H. S. Kang, Analysis of Recognition of Substitute Employment of Medical Personnel due to the Technology of the 4th Industrial Revolution, Eulji University, Master's Thesis, (2018)

[25] S. Taylor and P. A. Todd, Understanding Information Technology Usage: a Test of Competing Models, Information Systems Research, (1995), Vol.6, No.2, pp.144-176.

[26] H. R. Choi and J. S. Shin, The Impact of Users' Technology Readiness on the New Services Acceptance: Focus on Mobile Banking Services, Journal of Industrial Economics and Business, (2006), Vol.19, No.1, pp.131-155, UCI: G704-001438.2006.19.1.015 